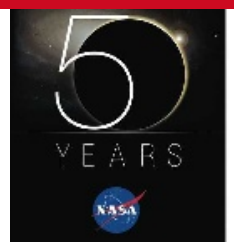

NASA AT 50

Past glories and future challenges.

www.nature.com/news

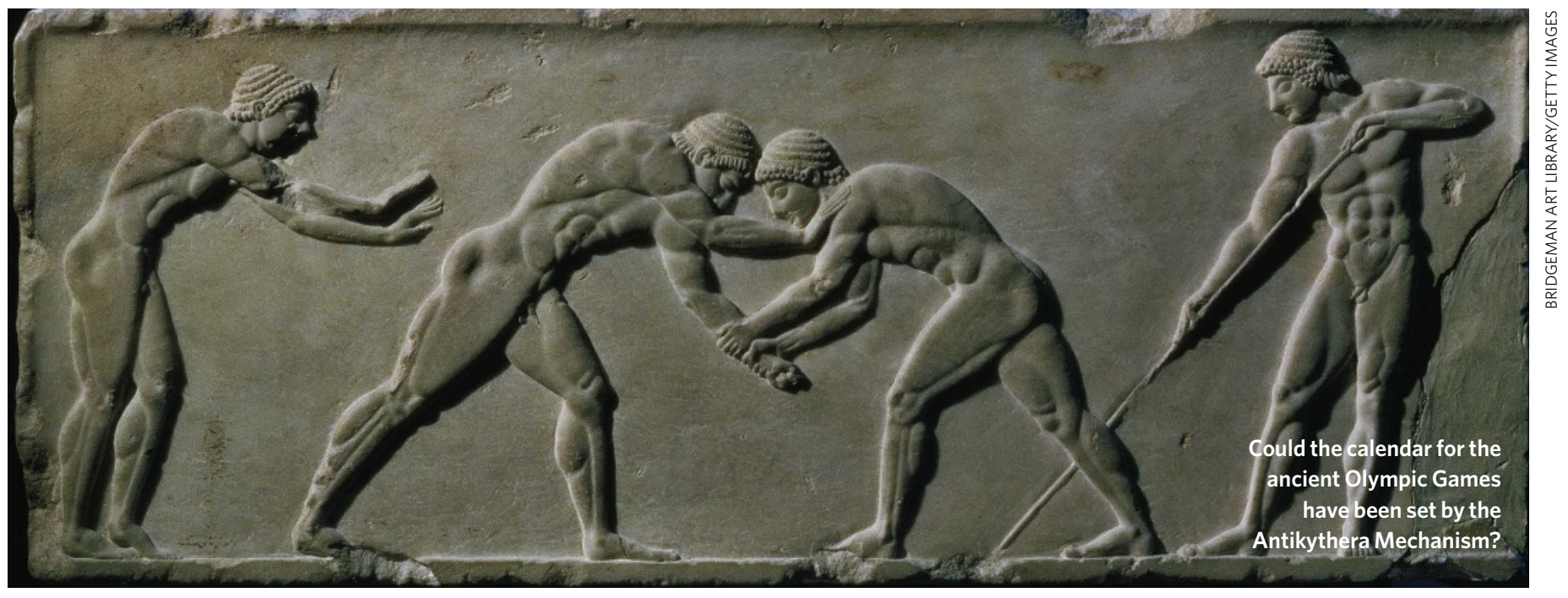

\title{
Complex clock combines calendars
}

The Antikythera Mechanism, a clockwork device made in Greece around 150-100 вс, astounded the world two years ago when scientists deduced how this machine was used to make complex astronomical time-reckonings. Now they say that the instrument, discovered in 1901 in a Mediterranean shipwreck, did much more than that.

Researchers have been trying to decode the mechanism's inscriptions and functions for several years. Their latest findings reveal that it links the technical calendars used by astronomers to the everyday calendars that regulated ancient Greek society - most strikingly, the calendar that set the timing of the Olympic Games.

"The mechanism is full of surprises," says Alexander Jones of the Institute for the Study of the Ancient World in New York, who is one of the decoding team. "The latest revelations establish its cultural origin for the first time."

The Olympic Games marked the beginning of a four-year timespan called an Olympiad: a calendar system shared by all the Greek citystates, bringing some uniformity to the chronology of the Hellenistic world. The Games began on the full Moon closest to the summer solstice, which meant that calculating the timing required expertise in astronomy. The Olympic Games were the most prestigious of four sets of games in ancient Greece, called the Panhellenic Games. First recorded in 776 BC, the ancient Olympic Games continued until they were extinguished by a ban from the Christian Roman emperor Theodosius I in around $394 \mathrm{AD}$.

The latest decoding of the Antikythera Mechanism (see page 614), by British mathematician Tony Freeth of the film company Images
First in London and his colleagues, casts fresh light on the way these calendar schemes were planned, used and integrated ${ }^{1}$. The device had intermeshed toothed wheels that represent calendar cycles. By turning the wheels, a user could figure out the relationships between astronomical cycles to deduce the relative positions of the Sun and Moon and forecast eclipses.

But after two millennia under the sea off the island of Antikythera, near Crete, all that remains of the device are 82 fragments of flaking bronze, including parts of 30 gear-wheels ${ }^{2}$. The numbers of gear teeth are crucial,

but must be inferred from the partial wheels that remain. And most of the inscriptions are hidden under corrosion and surface accretions. To read them, the researchers used a method called microfocus X-ray computed tomography, which provides X-ray images of slices through the sample, revealing inscriptions buried beneath the mechanism's surface.

In 2006, Freeth was part of a team that used this and other techniques to figure out much of the mechanism's function, showing it to be an instrument of unparalleled sophistication in antiquity, more or less unrivalled until the clockwork mechanisms of the later Middle Ages ${ }^{3}$.

Now they say that the device was even more sophisticated than that - it unites abstruse astronomical determinations of time with the calendar of civic society. Another ancient Greek calendar cycle, called the Metonic cycle, was established to cope with the incommensurability of the lunar cycle and the solar year - the period of Earth's rotation around the Sun, as determined, say, by the time between successive summer solstices. One Metonic period is equal to 235 lunar months, which is almost exactly 19 solar years. The Metonic cycle, thought previously to be used only by astronomers, is represented on a dial on the Antikythera Mechanism. But this dial now turns out to be inscribed with the names of months in a regional calendar used in Corinthian colonies in northwest Greece - providing evidence that the device was used for mundane reckonings, and giving a surprising clue to its origin.

As most of the cargo of the Antikythera wreck was from the eastern Mediterranean, researchers had thought that this was here the Mechanism originated too. But Freeth and his team now think that the instrument may have come from Syracuse in Sicily, the Corinthian colony where Archimedes devised a planetarium in the third century BC. "Archimedes died at the siege of Syracuse in 212 BC, so we are confident that he did not make the mechanism," says Freeth. "But it is possible that it came from a heritage of instrument-making that originated with him in Syracuse. It is an attractive idea, but purely speculative at present."

The Olympiad cycle appears on a subsidiary dial inside the Metonic dial, previously thought to represent an improvement on the Metonic cycle called the Callippic cycle. "It really surprised us to discover that it showed the four-year cycle of ancient Greek games", says Freeth. "The mechanism always produces more surprises." Philip Ball

\footnotetext{
1. Freeth, T., Jones, A., Steele, J. M. \& Bitsakis, Y. Nature 454, 614-617 (2008).

2. Marchant, J. Nature 444, 534-538 (2006).

3. Freeth, T. et al. Nature 444,587-591 (2006)
}

See http://tinyurl.com/6f83dt for a video. 